Research article

Open Access

\title{
Wnt signalling in human breast cancer: expression of the putative Wnt inhibitor Dickkopf-3 (DKK3) is frequently suppressed by promoter hypermethylation in mammary tumours
}

\author{
Jürgen Veeck1, Nuran Bektas¹, Arndt Hartmann², Glen Kristiansen³, Uwe Heindrichs4,5, \\ Ruth Knüchel ${ }^{1}$ and Edgar Dahl1
}

\author{
1Molecular Oncology Group, Institute of Pathology, University Hospital of the RWTH, Aachen, Pauwelsstrasse 30, D-52074 Aachen, Germany \\ 2Department of Pathology, University of Erlangen, Krankenhausstrasse 12, D-91054 Erlangen, Germany \\ 3 Institute of Surgical Pathology, University Hospital Zürich, Schmelzbergstrasse 12, CH-8091 Zürich, Switzerland \\ ${ }^{4}$ Department of Gynecology, Breast Surgery and Mastology, University Hospital of the RWTH Aachen, Pauwelsstrasse 30, D-52074 Aachen, \\ Germany \\ ${ }^{5}$ Brustzentrum Aachen-Stadt, Pauwelsstrasse 30, D-52074 Aachen, Germany
}

Corresponding author: Edgar Dahl, edahl@ukaachen.de

Received: 29 May 2008 Revisions requested: 25 Jun 2008 Revisions received: 2 Sep 2008 Accepted: 30 Sep 2008 Published: 30 Sep 2008

Breast Cancer Research 2008, 10:R82 (doi:10.1186/bcr2151)

This article is online at: http://breast-cancer-research.com/content/10/5/R82

(c) 2008 Veeck et al.; licensee BioMed Central Ltd.

This is an open access article distributed under the terms of the Creative Commons Attribution License (http://creativecommons.org/licenses/by/2.0), which permits unrestricted use, distribution, and reproduction in any medium, provided the original work is properly cited.

\begin{abstract}
Introduction Expression of the putative Wnt signalling inhibitor Dickkopf-3 $(D K K 3)$ is frequently lost in human cancer tissues because of aberrant 5 '-cytosine methylation within the $D K K 3$ gene promoter. Since other Wnt signalling inhibitors have been reported to be targets of epigenetic inactivation in human breast cancer, we questioned if $D K K 3$ expression is also epigenetically silenced during breast carcinogenesis and therefore might contribute to oncogenic Wnt signalling commonly found in this disease.

Methods DKK3 mRNA expression and DKK3 promoter methylation were determined by RT-PCR, realtime PCR and methylation-specific PCR in breast cell lines $(n=9)$, normal breast tissues $(n=19)$ and primary breast carcinomas ( $n=$ 150), respectively. In vitro DNA demethylation was performed by incubating breast cell lines with 5-aza-2'-deoxycytidine and trichostatin A. DKK3 protein expression was analysed by immunohistochemistry in breast carcinomas $(n=16)$ and normal breast tissues $(n=8)$. Methylation data were statistically correlated with clinical patient characteristics. All statistical evaluations were performed with SPSS 14.0 software.

Results DKK3 mRNA was downregulated in $71 \%$ (five of seven) of breast cancer cell lines and in $68 \%$ of primary breast carcinomas (27 of 40) compared with benign cell lines and normal breast tissues, respectively. A DNA demethylating treatment of breast cell lines resulted in strong induction of $D K K 3$ mRNA expression. In tumourous breast tissues, DKK3 mRNA downregulation was significantly associated with $D K K 3$ promoter methylation $(p<0.001)$. Of the breast carcinomas, $61 \%$ (92 of 150) revealed a methylated $D K K 3$ promoter, whereas $39 \%$ (58 of 150 ) retained an unmethylated promoter. Loss of DKK3 expression in association with DKK3 promoter methylation $(p=0.001)$ was also confirmed at the protein level ( $p<0.001)$. In bivariate analysis, DKK3 promoter methylation was not associated with investigated clinicopathological parameters except patient age $(p=0.007)$.

Conclusions DKK3 mRNA expression and consequently DKK3 protein expression become frequently downregulated during human breast cancer development due to aberrant methylation of the DKK3 promoter. Since DKK3 is thought to negatively regulate oncogenic Wnt signalling, $D K K 3$ may be a potential tumour suppressor gene in normal breast tissue.
\end{abstract}

\section{Introduction}

The mammalian Dickkopf genes $(D K K)$ encode a class of extracellular signalling molecules that control cell fate during embryonic development and regulate tissue homeostasis in adults $[1,2]$. Four DKK gene members have been identified so far. $D K K 1, D K K 2$ and $D K K 4$ antagonise canonical $\mathrm{Wnt} / \beta$-catenin signalling by interaction with LDL-receptor-related proteins (LRP5 and LRP6) [3]. In contrast, DKK3 does not

DKK3: Dickkopf-3; FC: fold change; IRS: immunoreactivity score; JNK: c-Jun-kinase; LRP: LDL-receptor related protein; MSP: methylation-specific polymerase chain reaction; PCP: planar cell polarity pathway; RT-PCR: reverse transcription polymerase chain reaction; SD: standard deviation; siRNA: small interfering ribonucleic acid; TSA: trichostatin A. 
sequester LRPs or Wnt ligands $[2,4,5]$. Its function in antagonising nuclear $\beta$-catenin levels, designated as the hallmark of an activated Wnt pathway often found in human tumour tissues [6], has received conflicting reports [7-9]. Most evidence suggest $D K K 3$ exerts a tumour suppressive function by inhibiting a non-canonical Wnt signalling branch referred to as the planar cell polarity (PCP) pathway. The PCP pathway is characterised by the activation of c-Jun kinase (JNK) via recruitment of small GTPases of the Rho/Rac family [10]. It results in changes in cell adhesion, motility and polarity [11] rather than interfering with the networks of proliferation and differentiation, which is mediated by canonical $\mathrm{Wnt} / \beta$-catenin signalling [6].

In agreement with its putative tumour-suppressive function $[9,12-14] D K K 3$ is commonly downregulated in human cancers such as lung cancer [15-17], renal clear cell carcinoma [18], pancreatic cancer [19], leukaemia [20], prostate cancer [7,21], bladder cancer [22], melanoma [23] and gastrointestinal tumours [24]. In many of these diseases transcriptional loss is tightly associated with methylation of the $D K K 3$ promoter $[15,16,18,20-22,24]$, whereas in other malignancies the cause of downregulation remains to be elucidated or is not related to 5'-cytosine methylation [23]. A study on lung cancer revealed that the rate of $D K K 3$ methylation increased steadily from normal lung tissue, to low-grade and high-grade atypical adenomatous hyperplasia to invasive adenocarcinoma [25], suggesting a potential role of $D K K 3$ methylation in lung cancer progression. In mouse cancer models, $D K K 3$ has proved a promising therapeutic agent capable of repressing tumour progression, for example, in testicular germ cell cancer [14] and prostate cancer [13]. More recently, a breast cancer xenotransplantation model demonstrated that a single adenoviral-mediated intra-tumoural injection of a $D K K 3$ expression vector efficiently discontinued tumour growth, with the induction of apoptosis in these cells [26]. This suggests that DKK3 may have an important tumour-suppressive function that either prevents tumour initiation or attenuates cancer progression. Interestingly, loss of $D K K 3$ expression was first observed in numerous immortalised tumour-derived cell lines [27]. Immortalisation, that is escape from cellular senescence, is an early event in malignant transformation [28], so DKK3 could act as a tumour suppressor gene by mediating the effects of senescence stimuli. In concordance with this hypothesis, DKK3 expression was found to be elevated in organs with predominantly growth-arrested post-mitotic cells, for example in the heart and brain [29] and also in senescent prostate epithelial cells [30].

However, to the authors' knowledge, a comprehensive study on $D K K 3$ gene regulation and its implication in breast cancer has not yet been published. In our study we investigated $D K K 3$ mRNA expression, DKK3 protein expression and DKK3 promoter methylation in breast cell lines as well as in normal and malignant primary breast tissues. Our results demonstrate for the first time that $D K K 3$ expression is frequently downreg- ulated in human breast cancer as a consequence of aberrant DNA methylation within the $D K K 3$ gene promoter.

\section{Materials and methods \\ Patient material}

Nineteen matched tumour and normal tissue samples from breast cancer patients and 131 tissue samples from breast carcinomas were obtained from patients treated by primary surgery for breast cancer at the Departments of Gynecology at the University Hospitals of Aachen, Jena, Regensburg and Düsseldorf, Germany, between 1991 and 2005. The selection of cases was based on availability of tissue, and the sample was recruited in a non-selective, consecutive manner. Female patients presenting with unilateral, invasive breast cancer with no individual breast cancer history were included in the study. Exclusion criteria were: neo-adjuvant chemotherapy before surgery; presentation with secondary breast cancer; or peritumourous carcinoma in situ present in the tumour sample. Patient characteristics are shown in Table 1.

All patients gave informed consent for retention and analysis of their tissue for research purposes and the Institutional Review Boards of the participating centres approved the study.

Tumour histology was determined according to the criteria of the World Health Organization [31], while disease stage was assessed according to International Union Against Cancer [32]. Tumours were graded according to Bloom and Richardson, as modified by Elston and Ellis [33]. After surgery, tumour material was immediately snap-frozen in liquid nitrogen. Sections stained with haematoxylin and eosin were prepared for assessing the percentage of tumour cells; only samples containing more than $70 \%$ tumour cells were selected. Samples were dissolved in lysis buffer followed by DNA isolation using the QIAamp DNA Mini Kit (Qiagen, Hilden, Germany) according to the manufacturer's recommendations.

\section{Breast cell lines}

The cancerous breast cell lines BT20, Hs578T, MCF7, MDAMB231, SKBR3, T47D and ZR75-1 and the non-cancerous lines HMEC and MCF12A were obtained from the American Type Culture Collection (ATCC) (Rockville, MA, USA) and cultured under recommended conditions.

\section{RNA expression analysis}

RNA isolation, RT-PCR and realtime PCR were performed as previously described [34]. To ensure experiment accuracy, all quantitative measurements were performed in triplicate. Intron-spanning primer sequences and cycling conditions are given in Table 2.

Bisulphite-modification and methylation-specific PCR About $1 \mu \mathrm{g}$ of genomic DNA was bisulphite-modified using the EZ DNA Methylation Kit (Zymo Research, Orange, CA, USA) 
Table 1

Demographic and clinical patient characteristics of primary breast carcinomas $(n=150)$

$\begin{array}{lll}\text { Variable } & \text { Categorisation } & \mathbf{n}^{1}\end{array}$

Clinicopathological factors

Age at diagnosis

median: 57 years (range 28 to 86 years)

$\begin{array}{lll}<57 \text { years } & 74 & 49.3 \\ =57 \text { years } & 76 & 50.7\end{array}$

Tumour size ${ }^{2}$

$\begin{array}{lcc}\text { pT1 } & 59 & 39.3 \\ \text { pT2 } & 70 & 46.7 \\ \text { pT3 } & 8 & 5.3 \\ \text { pT4 } & 10 & 6.7 \\ \text { pTx } & 3 & 2.0 \\ & & \\ \text { pN0 } & 72 & 48.0 \\ \text { pN1 to 3 } & 71 & 47.3 \\ \text { PNx } & 7 & 4.7\end{array}$

Histological grade

$\begin{array}{llc}\text { G1 } & 13 & 8.7 \\ \text { G2 } & 75 & 50.0 \\ \text { G3 } & 62 & 41.3\end{array}$

Histological type

$\begin{array}{lcc}\text { Ductal } & 122 & 81.3 \\ \text { Lobular } & 19 & 12.7 \\ \text { Other } & 9 & 6.0\end{array}$

Immunohistochemistry

Oestrogen receptor

Negative (IRS ${ }^{3} 0$ to -2$)$

Positive (IRS 3 to 12 )

n.a.

Progesterone receptor

\begin{tabular}{lcc} 
Negative (IRS 30 to 2$)$ & 51 & 34.0 \\
Positive (IRS 3 to 12) & 94 & 62.7 \\
n.a. & 5 & 3.3 \\
\hline
\end{tabular}

${ }_{1}^{1}$ Only female patients with unilateral invasive breast cancer were included. ${ }^{2}$ According to International Union Against Cancer: TNM Classification of Malignant Tumours [32]. ${ }^{3} \mathrm{IRS}=$ immunoreactivity score [35]. n.a. $=$ not available.

according to the manufacturer's recommendations. Methylation-specific PCR (MSP) was performed as previously described [34]. Primers and cycling conditions are listed in Table 2. Specificity of MSP primers in detecting the DKK3 methylation status were demonstrated using universal unmeth- ylated and universal polymethylated DNA as a template (Epi Tect Control DNA Set; Qiagen, Hilden, Germany). 
Table 2

Oligonucleotide primers used in the study

\begin{tabular}{|c|c|c|c|c|c|}
\hline & Sequence (5' to $\left.3^{\prime}\right)$ & $\mathrm{T}_{\mathrm{A}}\left[{ }^{\circ} \mathrm{C}\right]$ & Primer [nM] & Cycles & Product size (bp) \\
\hline \multicolumn{6}{|l|}{$R T-P C R$} \\
\hline \multirow[t]{3}{*}{ GAPDH } & Forward: TGGTCACCAGGGCTGCTT & \multirow{3}{*}{59} & \multirow{3}{*}{400} & \multirow{3}{*}{35} & \multirow{3}{*}{510} \\
\hline & & & & & \\
\hline & Reverse: GTCTTCTGGGTGGCAGTGAT & & & & \\
\hline \multirow[t]{3}{*}{ DKK3 } & Forward: AAGGCAGAAGGAGCCACGAGTGC & \multirow{3}{*}{59} & \multirow{3}{*}{400} & \multirow{3}{*}{35} & \multirow{3}{*}{182} \\
\hline & & & & & \\
\hline & Reverse: GGCCATTTTGGTGCAGTGACCCCA & & & & \\
\hline \multicolumn{6}{|c|}{ Semiquantitative realtime $P C R$} \\
\hline \multirow[t]{3}{*}{ GAPDH } & Forward: ATGGCCAGCGGGAAGAC & \multirow{3}{*}{60} & \multirow{3}{*}{500} & \multirow{3}{*}{40} & \multirow{3}{*}{289} \\
\hline & & & & & \\
\hline & Reverse: ATGGCCAGCGGGAAGAC & & & & \\
\hline \multirow[t]{3}{*}{ DKK3 } & Forward: ACAGCCACAGCCTGGTGTA & \multirow{3}{*}{60} & \multirow{3}{*}{400} & \multirow{3}{*}{40} & \multirow{3}{*}{123} \\
\hline & & & & & \\
\hline & Reverse: CCTCCATGAAGCTGCCAAC & & & & \\
\hline \multicolumn{6}{|c|}{ Methylation-specific PCR } \\
\hline \multirow[t]{3}{*}{ DKK3 unmethylated } & Forward: TTAGGGGTGGGTGGTGGGGT & \multirow{3}{*}{58} & \multirow{3}{*}{320} & \multirow{3}{*}{34} & \multirow{3}{*}{126} \\
\hline & & & & & \\
\hline & Reverse: СТАСАТСТССАСТСТАСАСССА & & & & \\
\hline \multirow[t]{3}{*}{ DKK3 methylated } & Forward: GGGCGGGCGGCGGGGC & \multirow{3}{*}{58} & \multirow{3}{*}{320} & \multirow{3}{*}{34} & \multirow{3}{*}{120} \\
\hline & & & & & \\
\hline & Reverse: ACATCTCCGCTCTACGCCCG & & & & \\
\hline
\end{tabular}

$\mathrm{T}_{\mathrm{A}}=$ annealing temperature.

\section{5-aza-2'-deoxycytidine and trichostatin A treatment}

DNA demethylating treatment of breast cancer cell lines was performed with 5-aza-2'-deoxycytidine as described elsewhere [34], modified by the addition of $300 \mathrm{nM}$ of the histone deacetylase inhibitor trichostatin A (Sigma-Aldrich, Deisenheim, Germany) on day three (incubation for 24 hours). Drug concentrations were adjusted in advance to warrant viability and replication of all cell lines.

\section{Immunohistochemistry}

Formalin-fixed, paraffin-embedded $2 \mu \mathrm{m}$ tissue sections were subjected to immunostaining using the Advance Kit (Dako, Hamburg, Germany) following the manufacturer's instructions. Antigen retrieval was performed by pre-treatment with citrate buffer $(\mathrm{pH} \mathrm{7})$ in a microwave oven (20 minutes at $200 \mathrm{~W}$ ). Sections were incubated for 30 minutes with the primary antibody (AP1523a, Abgent, San Diego, CA, USA; 1:50), washed and incubated for 10 minutes with the secondary antibody (biotinylated polylink; Dako, Hamburg, Germany). Diaminobenzidin (Dako, Hamburg, Germany) was used for antibody detection. An experienced breast cancer pathologist (N.B.) scored the immunohistochemical staining according to the scoring system suggested by Remmele and Stegner [35]. The tissue specimens for immunohistochemical analysis are characterised in Table 3. 
Table 3

Immunohistochemical analysis of DKK3 protein expression in breast cancer samples $(n=16)$ in relation to clinicopathological parameters

\begin{tabular}{|c|c|c|c|c|c|c|c|c|c|}
\hline Age & Size $^{1}(p T)$ & Node status $^{1}(\mathrm{pN})$ & Grade & Histology & $\mathrm{ER}^{2}$ & $\mathrm{PR}^{2}$ & $D K K 3$ methylation & DKK3 IRS tumour ${ }^{3}$ & DKK3 IRS normal 4 \\
\hline 49 & 1 & 0 & 3 & IDC & - & - & - & 9 & 12 \\
\hline 85 & 2 & 1 & 3 & IDC & - & - & n.a. & 3 & n.a. \\
\hline 69 & 2 & 1 & 2 & ILC & - & - & - & 9 & 12 \\
\hline 82 & 3 & 1 & 3 & IDC & - & - & + & 6 & n.a. \\
\hline 45 & 1 & 1 & 3 & IDC & - & - & + & 4 & 12 \\
\hline 60 & 3 & 0 & 3 & IDC & - & - & n.a. & 8 & n.a. \\
\hline 61 & 1 & 0 & 2 & IDC & - & - & + & 0 & n.a. \\
\hline 72 & 1 & 0 & 2 & IDC & - & - & n.a. & 4 & n.a. \\
\hline 44 & 1 & 1 & 3 & IDC & - & - & - & 12 & 12 \\
\hline 86 & 2 & n.a. & 3 & IDC & - & - & - & 8 & n.a. \\
\hline 60 & 1 & 1 & 3 & IDC & + & - & + & 2 & 9 \\
\hline 66 & 1 & 0 & 2 & IDC & + & + & + & 3 & n.a. \\
\hline 54 & 2 & 0 & 3 & IDC & + & - & + & 6 & 12 \\
\hline 83 & 1 & 0 & 2 & IDC & + & + & - & 9 & n.a. \\
\hline 79 & 2 & 0 & 3 & IDC & + & + & - & 8 & 12 \\
\hline 62 & 4 & 1 & 3 & IDC & + & - & + & 3 & 9 \\
\hline
\end{tabular}

${ }_{1}^{1}$ According to International Union Against Cancer: TNM Classification of Malignant Tumours [32]. ${ }^{2}$ According to Remmele and Stegner [35].

${ }^{3}$ According to Remmele and Stegner [35] as a continuous variable. ${ }^{4}$ Matched normal breast epithelial tissue. IRS $=$ immunoreactivity score. IDC $=$ invasive ductal carcinoma. ILC = invasive lobular carcinoma. n.a. = not available.

\section{Statistical evaluations}

Statistical analyses were completed using SPSS 14.0 (SPSS, Chicago, IL, USA). Differences were considered significant when $\mathrm{p}<0.05$. A non-parametric Mann-Whitney $U$-test and a Kruskal-Wallis test were applied to examine expression levels among normal tissues, DKK3 unmethylated tumours and $D K K 3$ methylated tumours. A student's t-test was applied on the expression of paired normal and tumour samples. To study statistical associations between clinicopathological factors and DKK3 methylation status contingency tables and a twosided Fisher's exact test were used.

\section{Results}

\section{Differential DKK3 mRNA expression in breast cell lines}

To start our analysis of $D K K 3$ expression in breast cancer patients we analysed mRNA expression in non-malignant and malignant breast cell lines using realtime PCR. Strong DKK3 expression could be detected in non-malignant HMEC and MCF12A cells (Figure 1a) exhibiting expression levels comparable with human placental tissue, which is known to abundantly express $D K K 3$ [22]. Among the malignant cell lines, Hs578T and SKBR3 cells revealed abundant DKK3 mRNA levels comparable with benign breast cells. In five further breast cancer cell lines (BT20, MCF7, MDA-MB231, T47D and ZR75-1) DKK3 expression was substantially reduced.

\section{Methylation of the DKK3 promoter in breast cell lines}

Aberrant promoter hypermethylation of tumour suppressor genes during carcinogenesis is an effective mechanism resulting in downregulation and functional inactivation of these genes [36,37]. Knowing that $D K K 3$ expression was downregulated in most malignant breast cell lines we performed promoter methylation analysis in these cells. By using MSP [38] we found a methylated $D K K 3$ promoter sequence in all cell lines showing reduced $D K K 3$ expression, BT20, MCF7, MDAMB231, T47D and ZR75-1 (Figure 1b). In contrast to this, all DKK3 expressing cell lines (HMEC, MCF12A, Hs578T and SKBR3) as well as human placental tissue lacked DKK3 promoter methylation in the analysed promoter region.

\section{In vitro demethylation of the DKK3 promoter}

To prove a direct association of $D K K 3$ promoter methylation with loss of $D K K 3$ mRNA expression we treated seven breast cell lines sequentially with the DNA-methyltransferase inhibitor 5-aza-2'-deoxycytidine and the histone deacetylase inhibitor trichostatin A. Subsequently, we determined DKK3 promoter methylation and DKK3 mRNA expression before and after the drug treatment. MSP analyses after the treatment (Figure 2a) confirmed that promoter demethylation had occurred in all methylated cell lines by the appearance and enhancement of signals indicative of unmethylated DNA sequences. Those cell lines initially bearing a methylated $D K K 3$ promoter showed 
Figure 1

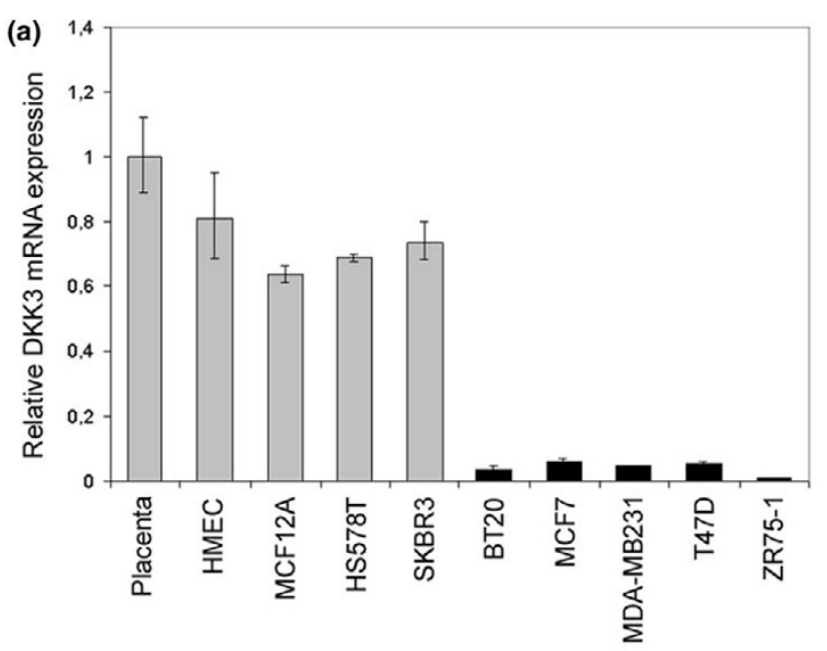

(b)

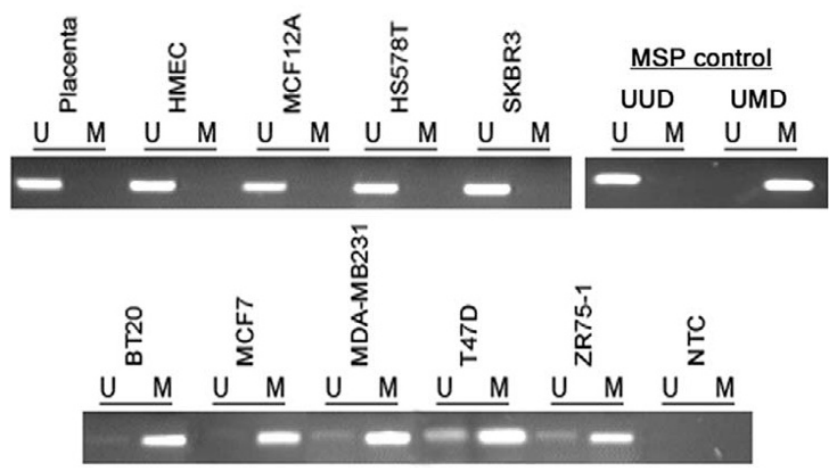

$D K K 3$ mRNA expression and $D K K 3$ promoter methylation analysis in breast cell lines. (a) DKK3 mRNA expression is differentially expressed in breast cell lines. Non-cancerous cell lines (HMEC and MCF12A) and cancerous breast cell lines (Hs578T, SKBR3, BT20, MCF7, MDA-MB231, T47D and ZR75-1) were analysed by realtime $\mathrm{PCR}$ and related to $D K K 3$ mRNA expression in human placental tissue (set to 1). Grey bars = samples expressing abundant $D K K 3$ mRNA; black bars $=$ samples showing strong downregulation of $D K K 3$ expression. (b) Hypermethylation of the $D K K 3$ promoter in breast cell lines. Methylation specific PCR (MSP) was performed with bisulphite-treated DNA from benign and malignant breast cell lines. DNA bands in lanes labelled with $U$ indicate PCR products amplified with primers recognising unmethylated $D K K 3$ promoter sequence. DNA bands in lanes labelled with $\mathrm{M}$ represent amplificate generated with methylation-specific primers; water served as 'no template control' (NTC). MSP controls demonstrate the specificity of the $D K K 3$ primers used. Universal poly-methylated bisulphite-converted DNA (UMD) exclusively yields amplification products with primers specific to methylated DKK3 promoter sequence; universal unmethylated bisulphite-converted DNA (UUD) yields exclusive amplification products with primers recognising the unmethylated $D K K 3$ promoter sequence.

elevated DKK3 mRNA expression after treatment (BT20, MCF7, MDA-MB231, T47D and ZR75-1; Figure 2b), whereas no DKK3 mRNA gain was achieved in unmethylated MCF12A and only a marginal DKK3 mRNA gain in SKBR3 cells. The induction of $D K K 3$ mRNA transcription after the treatment as
Figure 2
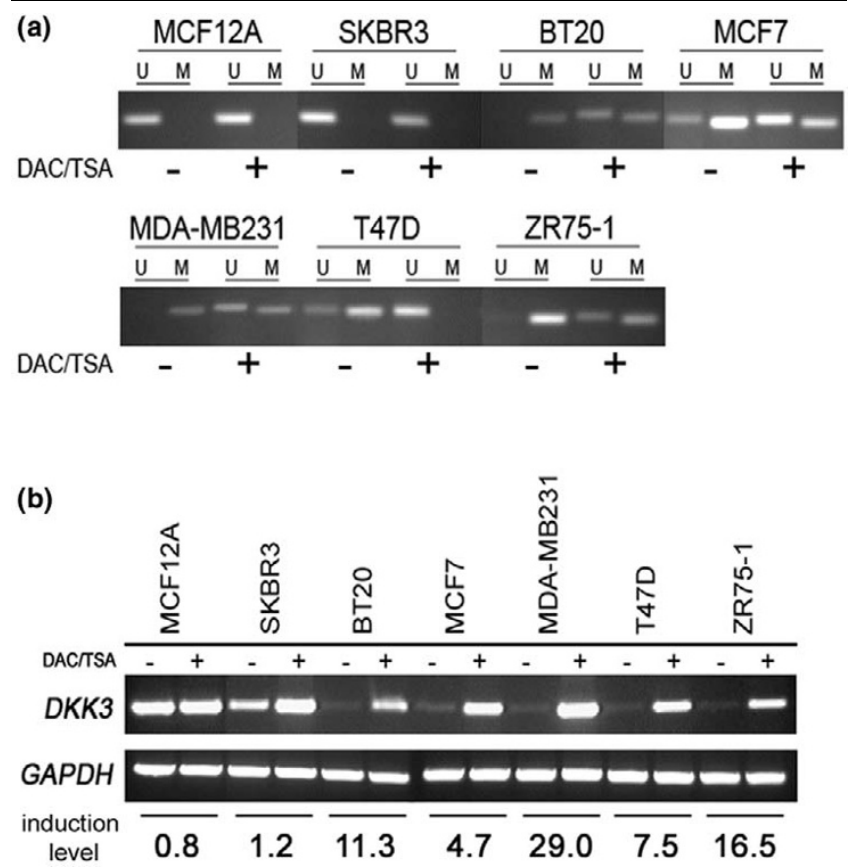

DKK3 mRNA expression after in vitro DNA demethylation. (a) In vitro demethylation of the $D K K 3$ promoter. Methylation specific PCR of seven breast cell lines was performed with DNA from cells either untreated (-) or treated with $1 \mu \mathrm{M}$ 5-aza-2'-deoxycytidine (DAC) and $300 \mathrm{nM}$ trichostatin A (TSA) (+). (b) Re-expression of DKK3 mRNA in breast cell lines after treatment with DAC/TSA. All cell lines initially exhibiting low $D K K 3$ mRNA restored expression of $D K K 3$ compared with the untreated control cells. Induction level (fold change) of $D K K 3$ mRNA expression was determined by realtime PCR.

determined by realtime PCR ranged from 4.7-fold to 29-fold higher than in originally methylated breast cancer cells.

\section{Differential DKK3 mRNA expression in primary breast carcinomas}

$D K K 3$ mRNA expression in primary breast tissues was then examined by realtime PCR. In the first step, 19 pairs of breast carcinoma tissues and corresponding normal breast tissue were analysed. A significant downregulation of DKK3 mRNA expression in tumour tissue compared with its adjacent normal tissue was detected in $14(74 \%)$ of the 19 pairs (Figure 3a), as defined by an expression fold change of two or more (FC2).

To further support this data set we analysed 40 additional breast carcinomas with no corresponding normal breast tissue and referred each individual $D K K 3$ mRNA expression level to the mean $D K K 3$ expression of the previously analysed 19 normal breast tissues (Figure $3 \mathrm{~b}$ ). The frequency of DKK3 mRNA downregulation measured in this tumour cohort (27 of 40, $68 \%$ by FC2) is in good agreement to the result achieved with the 19 matched pairs. Therefore downregulation of $D K K 3$ mRNA in breast cancer is considered to affect about $70 \%$ of patients. 


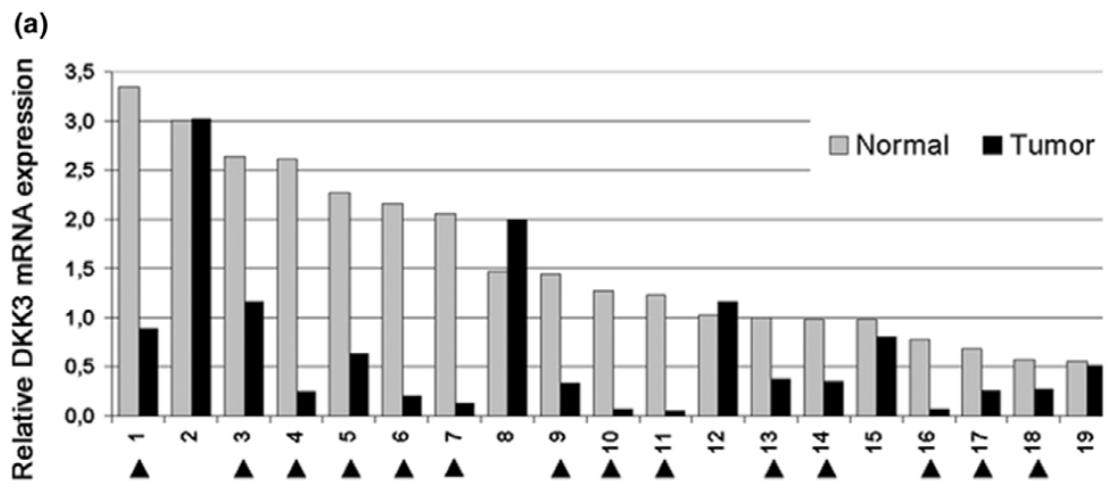

(b)

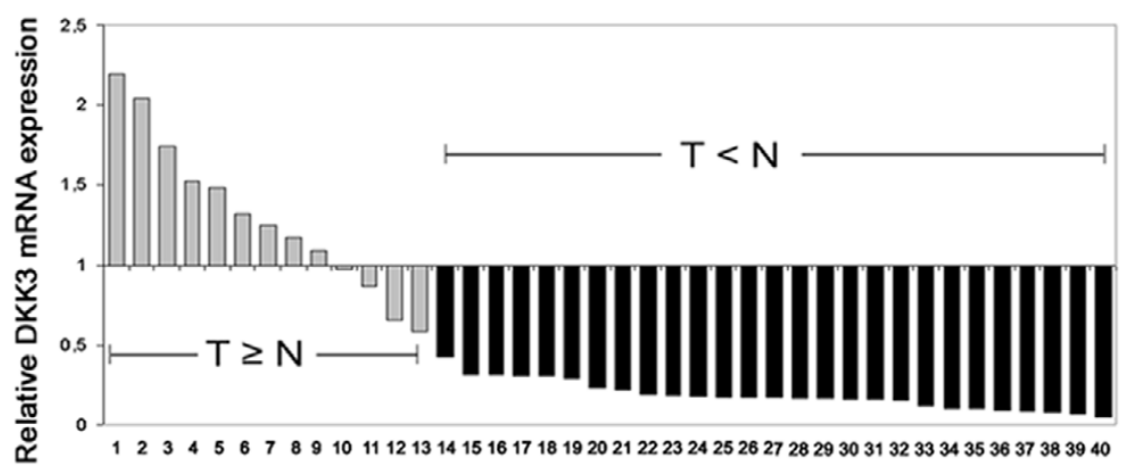

DKK3 mRNA expression analysis in primary breast carcinomas. (a) Realtime PCR of DKK3 mRNA expression in 19 matched pairs (normal vs. tumour). Arrowheads indicate downregulation in the tumour by an expression fold change of more than two (FC2). (b) Relative DKK3 mRNA expression in 40 additional breast cancer specimens. Mean expression of 19 normal breast tissues (N) was set to 1 . Based on a FC2, grey bars represent tumour specimens $(\mathrm{T})$ showing normal expression, black bars represent tumour specimens with reduced DKK3 mRNA expression.

\section{DKK3 promoter methylation in primary breast carcinomas}

To address the question of whether DKK3 promoter methylation occurs in primary breast carcinomas, we analysed 150 mammary tumour samples by MSP. Corresponding normal breast tissue was available for 19 tumours. In total, 92 of 150 tumours $(61.3 \%)$ revealed $D K K 3$ promoter methylation (for example, \#7 in Figure 4) whereas in 58 of 150 tumours (38.7\%) the DKK3 promoter was unmethylated. In these cases, MSP amplification signals were obtained exclusively in the U-reaction (for example, \#5 in Figure 4). Of the normal breast tissues, only a single sample (5.3\% of 19 samples) gave a very weak methylation signal (data not shown) in contrast to all other normal tissues that lacked $D K K 3$ promoter methylation. As an additional control that infiltrating immune cells do not contribute to methylation signals in mammary tumours, bisulphite-converted DNA from human peripheral blood lymphocytes were assayed and revealed an unmethylated $D K K 3$ promoter, consistent with results from a previous study [39].

\section{Correlation of $D K K 3$ promoter methylation with loss of DKK3 mRNA expression}

For all breast carcinoma samples analysed for DKK3 mRNA expression ( $\mathrm{n}=59$ ) we determined the DKK3 promoter methylation status at the same time. Thus, we were able to directly compare $D K K 3$ methylation and mRNA expression in primary human breast carcinomas. A boxplot (Figure 5) illustrates the distribution and medians of DKK3 RNA expression among normal breast tissues, $D K K 3$ unmethylated tumours and $D K K 3$ methylated tumours. The median DKK3 expression level (exp) of unmethylated tumours (exp =0.87; $F C=1.2$ ) was comparable with that of normal breast tissues (set to exp =1). In contrast, $D K K 3$ methylated tumours showed a significant $\mathrm{mRNA}$ downregulation (exp $=0.17 ; \mathrm{FC}=5.9$ ) compared with $D K K 3$ unmethylated tumours and normal breast tissue (global $p<0.001$ ).

\section{Differential $D K K 3$ protein expression in primary breast carcinomas}

Immunohistochemical staining was used to investigate DKK3 protein expression in normal $(n=8)$ and malignant $(n=16)$ 


\begin{tabular}{|c|c|c|c|c|c|c|c|c|c|}
\hline \multicolumn{2}{|c|}{ \#1 } & \multicolumn{2}{|c|}{ \#2 } & \multicolumn{2}{|c|}{$\# 3$} & \multicolumn{2}{|c|}{$\# 4$} & \multicolumn{2}{|c|}{$\# 5$} \\
\hline$\underline{T}$ & $\mathrm{~N}$ & $\underline{T}$ & $\underline{N}$ & $\underline{T}$ & $\mathrm{~N}$ & $\underline{T}$ & $\mathrm{~N}$ & $\underline{T}$ & $\mathrm{~N}$ \\
\hline$U M$ & $U \mathrm{M}$ & $\mathrm{UM}$ & $\mathrm{U} \mathrm{M}$ & $\mathrm{UM}$ & $U \mathrm{M}$ & $\mathrm{UM}$ & $U \mathrm{M}$ & $U \mathrm{M}$ & $U \mathrm{M}$ \\
\hline
\end{tabular}

\begin{tabular}{|c|c|c|c|c|c|c|c|c|c|}
\hline \multicolumn{2}{|c|}{$\# 6$} & \multicolumn{2}{|c|}{$\# 7$} & \multicolumn{2}{|c|}{$\# 8$} & \multicolumn{2}{|c|}{$\# 9$} & \multicolumn{2}{|c|}{$\# 10$} \\
\hline$\underline{T}$ & $\underline{N}$ & $\underline{T}$ & $\underline{N}$ & $\underline{T}$ & $\underline{N}$ & $\underline{T}$ & $\underline{N}$ & $\underline{T}$ & $\underline{N}$ \\
\hline $\mathrm{U} \mathrm{M}$ & $\mathrm{U} \mathrm{M}$ & $\underline{U}$ & U M & U M & U M & U M & $\mathrm{U} \mathrm{M}$ & $\underline{U}$ & $\underline{\mathrm{U}} \mathrm{M}$ \\
\hline- & - & - & - & - & - & - & - & - & - \\
\hline
\end{tabular}

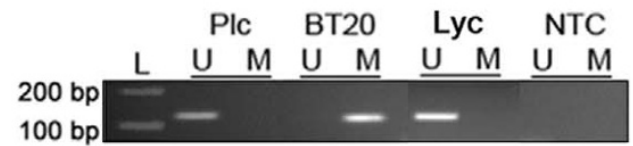

$D K K 3$ promoter methylation analysis in primary breast carcinomas. Methylation specific PCR results from 10 representative matched pairs of primary breast tumour $(\mathrm{T})$ and corresponding normal breast tissue $(\mathrm{N})$ are shown. DNA from human placenta (Plc) as well as from peripheral blood lymphocytes (Lyc) reveals an unmethylated DKK3 promoter. DNA from breast carcinoma cell line BT20 served as positive control. NTC $=$ no template control.

breast tissues. DKK3 was strongly expressed in non-malignant luminal and basal epithelial cells, achieving a mean (sd) immunoreactivity score (IRS) [34] of 11.3 (1.4) (Figure 6a) and a

Figure 5

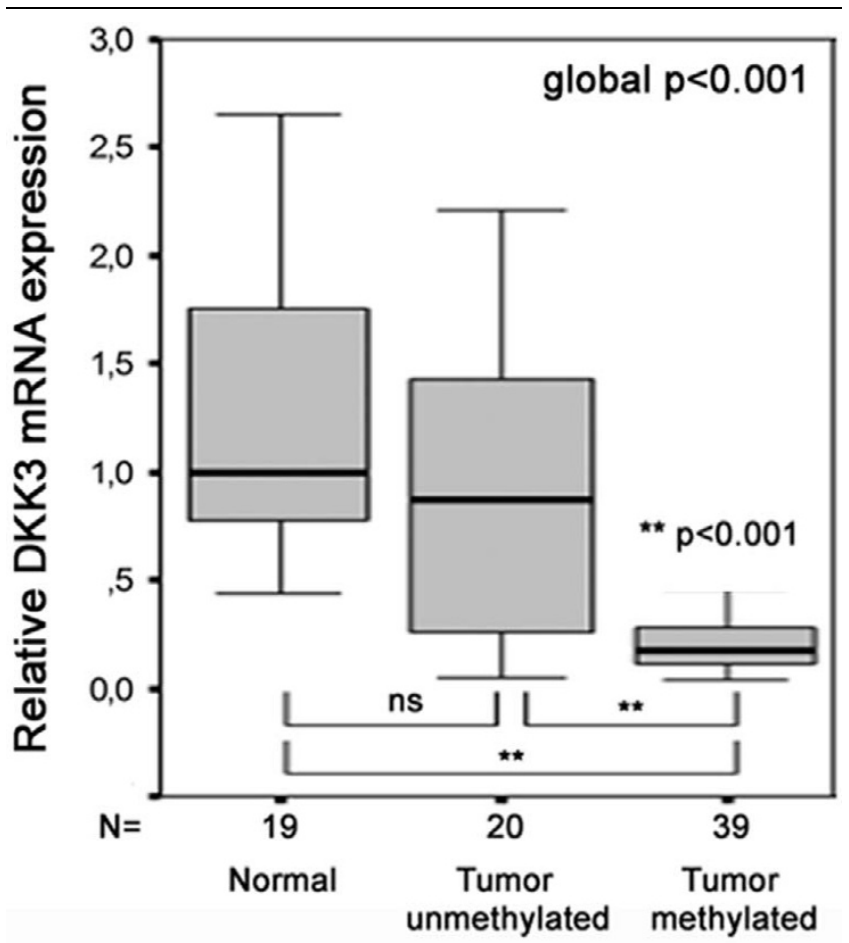

Correlation analysis of $D K K 3$ promoter methylation with $D K K 3$ mRNA expression in primary breast carcinomas. Tumours that are unmethylated in the $D K K 3$ promoter express $D K K 3$ mRNA comparable with $D K K 3$ mRNA expression normal breast tissue, whereas in $D K K 3$ methylated tumours $D K K 3$ mRNA expression is significantly reduced. Horizontal lines = group medians; boxes $=25$ to $75 \%$ quartiles, range, peak and minimum. median IRS of 12 (range 9 to 12). DKK3 protein was not detectable in stromal cells in the normal breast tissue. Of the breast carcinomas, four of 16 (25\%) revealed abundant DKK3 protein expression (IRS $=9$ to 12 ; Figure $6 \mathrm{~b}$ ) in contrast to seven of 16 tumours (44\%), which showed partial loss (IRS = 4 to 8 ; Figure $6 \mathrm{c}$ ), and five of 16 tumours (31\%) with substantial loss of DKK3 protein (IRS $=0$ to 3 ; Figure $6 \mathrm{~d}$ and Table 3). The mean protein staining intensity in breast carcinomas was determined to have an IRS of 5.9 (3.3) and the median to have an IRS of 6 (range 0 to 12). DKK3 expression levels in the tumour and normal tissue groups were shown to be significantly different ( $p=0.002 ; U$-test), and DKK3 protein was also differentially expressed within the eight matched pairs $(p<$ 0.001 ; t-test). As a continuous variable, a lower IRS in breast carcinoma was significantly associated with the presence of $D K K 3$ promoter methylation ( $\mathrm{p}=0.001$; Fisher's exact test).

\section{Association of DKK3 promoter methylation with clinicopathological factors}

For descriptive data analysis clinicopathological patient characteristics were correlated with the $D K K 3$ promoter methylation status. In a bivariate analysis, DKK3 promoter methylation was significantly associated with advanced patient age at diagnosis $(p=0.007)$. Furthermore, $D K K 3$ promoter methylation was not associated with tumour size, lymph node status, histological grade, histological type, and oestrogen receptor or progesterone receptor positivity (data not shown).

\section{Discussion}

It was previously reported that expression of the putative Wnt antagonist $D K K 3$ was downregulated in several tumour entities as a consequence of epigenetic DNA modification $[15,16,18,20-22,24]$. Our study is the first to analyse $D K K 3$ gene regulation in human breast cancer. Malignant breast cell lines showed strong reduction of DKK3 mRNA in association 
Figure 6

(a)
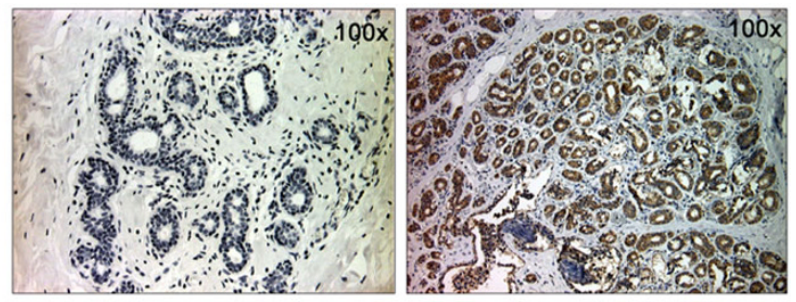

(b)
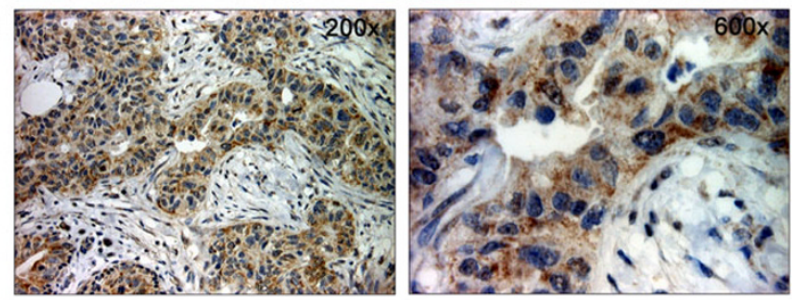

(c)
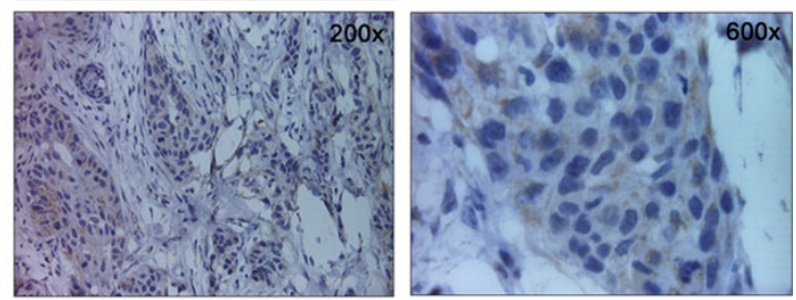

(d)

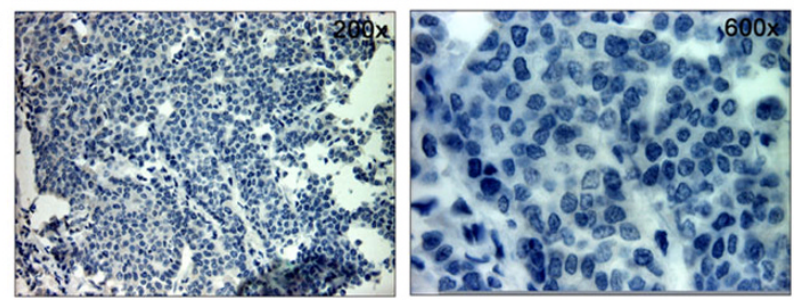

$D K K 3$ protein expression in primary breast carcinomas as determined by immunohistochemical staining. (a) Normal mammary tissue without (left) and with application (right) of $D K K 3$ antibody. Abundant $D K K 3$ protein expression is detectable in luminal and basal epithelial cells. (b) Breast carcinoma with unmethylated $D K K 3$ promoter reveals abundant $D K K 3$ protein expression. (c) and (d) Breast carcinomas with a methylated $D K K 3$ promoter exhibit substantial loss of $D K K 3$ protein expression. Original magnifications are given in upper right-hand corner.

with $D K K 3$ promoter methylation. Consistently, DKK3 mRNA expression was induced after promoter DNA demethylation in these cells. In primary breast carcinomas, DKK3 mRNA expression was downregulated in $68 \%$ of invasive tumours with significant association with methylation of the $D K K 3$ gene promoter $(\mathrm{p}<0.001)$. The total frequency of $D K K 3$ methylation was $61 \%$ in breast carcinomas, whereas corresponding normal breast tissues were unaffected by this epimutation. We further showed that a loss of DKK3 protein in breast carcinomas is also associated with $D K K 3$ promoter methylation ( $\mathrm{p}=$ 0.001 ) whereas protein expression is abundant in epithelial cells of the normal breast. In summary, our data demonstrate for the first time that promoter methylation-mediated downregulation of $D K K 3$ expression is a frequent and tumour-related epigenetic alteration in the development of human breast cancer.
The implication of aberrant canonical Wnt/ $\beta$-catenin signalling in the pathogenesis of human cancer has become widely accepted [40]. Its oncogenic effect is mediated by uncontrolled activation of target genes that for example, enhance cell proliferation, such as c-myc and cyclin D1. In breast cancer, several genes encoding inhibitors of canonical Wnt/ $\beta$-catenin signalling have been reported to be frequently hypermethylated, for example, SFRP1 [34,41], SFRP2 [42], SFRP5 [43], WIF1 [44] and DKK1 [42]. We suggest that disruption of a non-canonical Wnt signalling branch, the PCP pathway, may also be implicated in human carcinogenesis by pathologically altering the networks of cellular adhesion, motility and cell polarity, because it has been shown that expression of the putative PCP pathway inhibitor $D K K 3$ is commonly downregulated in malignant tissues. As a consequence, loss of $D K K 3$ may promote hyperactivation of the PCP pathway, thereby potentially enhancing tumour aggressiveness.

Recent in vivo experiments support a hypothesis that the loss of $D K K 3$ expression promotes an aggressive cancer phenotype. In a mouse model, $D K K 3$ proved to be a promising therapeutic agent to significantly inhibit tumour growth in testicular germ cell cancer [14]. In an orthotopic prostate cancer model a similar treatment resulted in tumour regression, decreased metastasis and prolonged survival of the host [13]. The most recent findings from a breast cancer study revealed that $D K K 3$ not only attenuates tumour growth in a xenotransplantation mouse model, it also re-sensitised multidrug-resistant MCF7/ ADR cells to doxorubicin treatment in a JNK-c-Jun dependent manner [26]. This highlights its potential utility as a gene therapeutic agent in human breast cancer. Our study adds important information to this aspect, because it so far remained unknown if methylation-mediated loss of $D K K 3$ expression also occurred in primary breast cancer, and, if so, how many patients were affected by this epimutation. We have shown that a large proportion (61\%) of breast cancer patients have $D K K 3$ promoter methylation in the carcinoma tissue, leading to a functional inactivation of the tumour-protective protein. Therefore, we conclude that a potential gene therapeutic treatment with $D K K 3$ might be of benefit for a large target population of breast cancer patients.

In contrast to other studies, DKK3 promoter methylation in our cohort was not associated with clinicopathological factors indicative of a progressive cancer subtype, such as tumour size, node status or histological grade. The existence of such an association has been demonstrated in prostate cancer [7,12], in which expression of $D K K 3$ was predominantly lost in high-grade prostatic tumours. Moreover, siRNA-mediated downregulation of $D K K 3$ expression in prostate epithelial cells disrupted acinar morphogenesis [7], which taken with its prevalent expression in growth-arrested cells suggests a functional role of $D K K 3$ in post-mitotic tissue differentiation processes. Whether $D K K 3$ is also involved in maintaining glandular mor- 
phology in the normal mammary gland will be elucidated in a further study.

In human breast cancer, hypermethylation of Wnt antagonist genes was reported to be of clinical relevance. Both SFRP1 and SFRP5 methylation were shown to occur frequently and be tumour specific with a strong association to poor clinical patient outcome [34,43]. An impact of DKK3 promoter methylation on cancer patient survival has been repeatedly found. It was shown to be associated with reduced disease-free survival in acute lymphoblastic leukaemia [20], and also with shorter overall survival in kidney cancer [45] and lung cancer [46]. Due to its functional properties as a potential tumour suppressor in human cancers including breast cancer [26], together with the finding that $D K K 3$ methylation is a significant prognostic factor in three human malignancies, we speculate that $D K K 3$ methylation might also bear prognostic power in breast cancer. This hypothesis is currently being approached in our laboratory in a further study.

In summary, we demonstrate for the first time that the Wnt antagonist gene $D K K 3$ is a frequent target of epigenetic inactivation in human breast cancer, leading to downregulation of $D K K 3$ mRNA and DKK3 protein expression in tumourous tissues. These results suggest a causative implication of $D K K 3$ in the development of human breast cancer. Since $D K K 3$ is believed to negatively regulate $\mathrm{Wnt}$ signalling, these results underline the pivotal role of a deregulated Wnt signalling pathway commonly found in this disease.

\section{Conclusion}

This study shows that the putative Wnt antagonist $D K K 3$ is frequently downregulated in human breast cancer due to promoter methylation, whereas it is abundantly expressed and unmethylated in normal breast cell epithelium. Since promoter methylation is a primary cause to functionally inactivate tumour suppressor genes, $D K K 3$ may act as a tumour suppressor in the human mammary gland. $D K K 3$ is believed to particularly regulate non-canonical Wnt signalling. Therefore, we conclude that disruption of this Wnt pathway branch may add further tumour growth advantages to those already conferred by canonical Wnt/ $\beta$-catenin signalling.

\section{Competing interests}

Edgar Dahl has declared that he has submitted a patent application on the use of $D K K 3$ promoter methylation. The other authors have no competing interests.

\section{Authors' contributions}

JV carried out the gene expression analyses, immunohistochemical studies, methylation experiments and statistical evaluations, participated in the conception and design of the study, and wrote the manuscript. NB participated in the immunohistochemical analysis, performed data interpretation and critically revised the manuscript. AH provided clinical samples and clinicopathological data, performed data interpretation, supported in statistical analyses and critically revised the manuscript. GK provided clinical samples and clinicopathological data, performed data interpretation and critically revised the manuscript. UH provided clinical samples and clinicopathological data, participated in data interpretation and critically revised the manuscript. RK participated in the design and coordination of the study and critically revised the manuscript. ED planned and co-ordinated the study, and critically revised the manuscript. All authors have given final approval of the text to be published.

\section{Acknowledgements}

The expert technical assistance of Sevim Alkaya, Sonja von Serényi and Inge Losen is greatly appreciated. We thank Dr Dieter Niederacher (Heinrich-Heine University, Düsseldorf, Germany) and Professor Matthias Dürst (Friedrich-Schiller University, Jena, Germany) for kindly providing patient samples. This work is a research project within the German Human Genome Project and has been supported by a Bundesministerium für Bildung und Forschung grant $01 \mathrm{KW} 0401$ to Edgar Dahl.

\section{References}

1. Glinka A, Wu W, Delius $H$, Monaghan AP, Blumenstock C, Niehrs C: Dickkopf-1 is a member of a new family of secreted proteins and functions in head induction. Nature 1998, 391:357-362.

2. Krupnik VE, Sharp JD, Jiang C, Robison K, Chickering TW, Amaravadi L, Brown DE, Guyot D, Mays G, Leiby K, Chang B, Duong T, Goodearl AD, Gearing DP, Sokol SY, McCarthy SA: Functional and structural diversity of the human Dickkopf gene family. Gene 1999, 238:301-313.

3. He X, Semenov M, Tamai K, Zeng X: LDL receptor-related proteins 5 and 6 in Wnt/beta-catenin signaling: arrows point the way. Development 2004, 131:1663-1677.

4. Mao B, Wu W, Li Y, Hoppe D, Stannek P, Glinka A, Niehrs C: LDLreceptor-related protein 6 is a receptor for Dickkopf proteins. Nature 2001, 411:321-325.

5. Mao B, Niehrs C: Kremen2 modulates Dickkopf2 activity during Wnt/LRP6 signaling. Gene 2003, 302:179-183.

6. Reya $T$, Clevers $H$ : Wnt signalling in stem cells and cancer. Nature 2005, 434:843-850.

7. Kawano Y, Kitaoka M, Hamada Y, Walker MM, Waxman J, Kypta RM: Regulation of prostate cell growth and morphogenesis by Dickkopf-3. Oncogene 2006, 25:6528-6537.

8. Yue W, Sun Q, Dacic S, Landreneau RJ, Siegfried JM, Yu J, Zhang $\mathrm{L}$ : Downregulation of Dkk3 activates beta-catenin/TCF-4 signaling in lung cancer. Carcinogenesis 2008, 29:84-92.

9. Hoang $\mathrm{BH}$, Kubo T, Healey JH, Yang R, Nathan SS, Kolb EA, Mazza B, Meyers PA, Gorlick R: Dickkopf 3 inhibits invasion and motility of Saos-2 osteosarcoma cells by modulating the Wntbeta-catenin pathway. Cancer Res 2004, 64:2734-2739.

10. Tada M, Concha ML, Heisenberg CP: Non-canonical Wnt signalling and regulation of gastrulation movements. Semin Cell Dev Biol 2002, 13:251-260.

11. Henderson DJ, Phillips HM, Chaudhry B: Vang-like 2 and noncanonical Wnt signaling in outflow tract development. Trends Cardiovasc Med 2006, 16:38-45.

12. Abarzua F, Sakaguchi M, Takaishi M, Nasu Y, Kurose K, Ebara S, Miyazaki M, Namba M, Kumon H, Huh NH: Adenovirus-mediated overexpression of REIC/Dkk-3 selectively induces apoptosis in human prostate cancer cells through activation of c-JunNH2-kinase. Cancer Res 2005, 65:9617-9622.

13. Edamura K, Nasu Y, Takaishi M, Kobayashi T, Abarzua F, Sakaguchi M, Kashiwakura Y, Ebara S, Saika T, Watanabe M, Huh NH, Kumon H: Adenovirus-mediated REIC/Dkk-3 gene transfer inhibits tumor growth and metastasis in an orthotopic prostate cancer model. Cancer Gene Ther 2007, 14:765-772.

14. Tanimoto R, Abarzua F, Sakaguchi M, Takaishi M, Nasu Y, Kumon $\mathrm{H}$, Huh NH: REIC/Dkk-3 as a potential gene therapeutic agent 
against human testicular cancer. Int J Mol Med 2007, 19:363-368.

15. Nozaki I, Tsuji T, lijima O, Ohmura Y, Andou A, Miyazaki M, Shimizu N, Namba M: Reduced expression of REIC/Dkk-3 gene in nonsmall cell lung cancer. Int $J$ Oncol 2001, 19:117-121.

16. Kobayashi K, Ouchida M, Tsuji T, Hanafusa H, Miyazaki M, Namba M, Shimizu N, Shimizu K: Reduced expression of the REIC/Dkk3 gene by promoter-hypermethylation in human tumor cells. Gene 2002, 282:151-158.

17. Tsuji T, Nozaki I, Miyazaki M, Sakaguchi M, Pu H, Hamazaki Y, lijima $\mathrm{O}$, Namba M: Antiproliferative activity of REIC/Dkk-3 and its significant down-regulation in non-small-cell lung carcinomas. Biochem Biophys Res Commun 2001, 289:257-263.

18. Kurose K, Sakaguchi M, Nasu Y, Ebara S, Kaku H, Kariyama R, Arao $\mathrm{Y}$, Miyazaki M, Tsushima T, Namba M, Kumon $\mathrm{H}$, Huh $\mathrm{NH}$ : Decreased expression of REIC/Dkk-3 in human renal clear cell carcinoma. J Urol 2004, 171:1314-1318.

19. Hsieh SY, Hsieh PS, Chiu CT, Chen WY: Dickkopf-3/REIC functions as a suppressor gene of tumor growth. Oncogene 2004, 23:9183-9189.

20. Roman-Gomez J, Jimenez-Velasco A, Agirre $X$, Castillejo JA, Navarro G, Barrios M, Andreu EJ, Prosper F, Heiniger A, Torres A: Transcriptional silencing of the Dickkopfs-3 (Dkk-3) gene by CpG hypermethylation in acute lymphoblastic leukaemia. $\mathrm{Br} J$ Cancer 2004, 91:707-713.

21. Lodygin D, Epanchintsev A, Menssen A, Diebold J, Hermeking $\mathrm{H}$ : Functional epigenomics identifies genes frequently silenced in prostate cancer. Cancer Res 2005, 65:4218-4227.

22. Urakami S, Shiina $\mathrm{H}$, Enokida $\mathrm{H}$, Kawakami T, Kawamoto $\mathrm{K}$, Hirata $\mathrm{H}$, Tanaka Y, Kikuno N, Nakagawa M, Igawa M, Dahiya R: Combination analysis of hypermethylated Wnt-antagonist family genes as a novel epigenetic biomarker panel for bladder cancer detection. Clin Cancer Res 2006, 12:2109-2116.

23. Kuphal S, Lodermeyer S, Bataille F, Schuierer $M$, Hoang $B H$, Bosserhoff AK: Expression of Dickkopf genes is strongly reduced in malignant melanoma. Oncogene 2006, 25:5027-5036.

24. Sato $H$, Suzuki $H$, Toyota $M$, Nojima M, Maruyama R, Sasaki S, Takagi H, Sogabe Y, Sasaki Y, Idogawa M, Sonoda T, Mori M, Imai K, Tokino T, Shinomura Y: Frequent epigenetic inactivation of DICKKOPF family genes in human gastrointestinal tumors. Carcinogenesis 2007, 28:2459-2466.

25. Licchesi JD, Westra WH, Hooker CM, Machida EO, Baylin SB, Herman JG: Epigenetic alteration of Wnt pathway antagonists in progressive glandular neoplasia of the lung. Carcinogenesis 2008, 29:895-904

26. Kawasaki K, Watanabe M, Sakaguchi M, Ogasawara $Y$, Ochiai K, Nasu $\mathrm{Y}$, Doihara $\mathrm{H}$, Kashiwakura $\mathrm{Y}$, Huh $\mathrm{NH}$, Kumon $\mathrm{H}$, Date $\mathrm{H}$ : REIC/Dkk-3 overexpression downregulates P-glycoprotein in multidrug-resistant MCF7/ADR cells and induces apoptosis in breast cancer. Cancer Gene Ther 2008. doi:10.1038/ cgt.2008.58

27. Tsuji T, Miyazaki M, Sakaguchi M, Inoue Y, Namba M: A REIC gene shows down-regulation in human immortalized cells and human tumor-derived cell lines. Biochem Biophys Res Commun 2000, 268:20-24.

28. Namba M, Tsuji T: Early events during neoplastic transformation of human cells in vitro: Genetic and biological aspects of immortalization. In Molecular Pathology of Early Cancer Edited by: Srivastava S, Henson DE, Gazdar A. Amsterdam: IOS Press; 1999:27-38

29. Monaghan AP, Kioschis $P$, Wu W, Zuniga A, Bock D, Poustka A Delius $H$, Niehrs C: Dickkopf genes are co-ordinately expressed in mesodermal lineages. Mech Dev 1999, 87:45-56.

30. Tavassoli FA, Devilee P: World Health Organization Classification of Tumours. Pathology and Genetics of Tumours of the Breast and Female Genital Organs. Lyon: IARC Press; 2003.

31. Untergasser G, Koch HB, Menssen A, Hermeking H: Characterization of epithelial senescence by serial analysis of gene expression: identification of genes potentially involved in prostate cancer. Cancer Res 2002, 62:6255-6262.

32. Sobin LH, Wittekind C, eds: TNM classification of malignant tumors. 5th edition. New York: Wiley Liss; 1997.

33. Elston EW, Ellis IO: Method for grading breast cancer. J Clin Pathol 1993, 46:189-190.
34. Veeck J, Niederacher D, An H, Klopocki E, Wiesmann F, Betz B, Galm O, Camara O, Dürst M, Kristiansen G, Huszka C, Knüchel R, Dahl E: Aberrant methylation of the Wnt antagonist SFRP1 in breast cancer is associated with unfavourable prognosis. Oncogene 2006, 25:3479-3488.

35. Remmele W, Stegner HE: [Recommendation for uniform definition of an immunoreactive score (IRS) for immunohistochemical estrogen receptor detection (ER-ICA) in breast cancer tissue]. Pathologe 1987, 8:138-140.

36. Das PM, Singal R: DNA methylation and cancer. J Clin Oncol 2004, 22:4632-4642.

37. Esteller M: Aberrant DNA methylation as a cancer-inducing mechanism. Annu Rev Pharmacol Toxicol 2005, 45:629-656.

38. Herman JG, Graff JR, Myohanen S, Nelkin BD, Baylin SB: Methylation-specific PCR: a novel PCR assay for methylation status of CpG islands. Proc Natl Acad Sci USA 1996, 93:9821-9826.

39. Román-Gómez J, Cordeu L, Agirre $X$, Jiménez-Velasco $A$, San José-Eneriz E, Garate L, Calasanz MJ, Heiniger A, Torres A, Prosper F: Epigenetic regulation of Wnt-signaling pathway in acute lymphoblastic leukemia. Blood 2007, 109:3462-3469.

40. Polakis P: Wnt signaling and cancer. Genes Dev 2000, 14:1837-1851.

41. Lo PK, Mehrotra J, D'Costa A, Fackler MJ, Garrett-Mayer E, Argani $P$, Sukumar S: Epigenetic suppression of secreted frizzled related protein 1 (SFRP1) expression in human breast cancer. Cancer Biol Ther 2006, 5:281-286.

42. Suzuki H, Toyota M, Caraway H, Gabrielson E, Ohmura T, Fujikane T, Nishikawa N, Sogabe Y, Nojima M, Sonoda T, Mori M, Hirata K, Imai K, Shinomura Y, Baylin SB, Tokino T: Frequent epigenetic inactivation of Wnt antagonist genes in breast cancer. $\mathrm{Br} J$ Cancer 2008, 98:1147-1156.

43. Veeck J, Geisler C, Noetzel E, Alkaya S, Hartmann A, Knüchel R, Dahl E: Epigenetic inactivation of the Secreted frizzled-related protein-5 (SFRP5) gene in human breast cancer is associated with unfavorable prognosis. Carcinogenesis 2008, 29:991-998

44. Ai L, Tao Q, Zhong S, Fields CR, Kim WJ, Lee MW, Cui Y, Brown KD, Robertson KD: Inactivation of Wnt inhibitory factor-1 (WIF1) expression by epigenetic silencing is a common event in breast cancer. Carcinogenesis 2006, 27:1341-1348.

45. Urakami $\mathrm{S}$, Shiina $\mathrm{H}$, Enokida $\mathrm{H}$, Hirata $\mathrm{H}$, Kawamoto K, Kawakami T, Kikuno N, Tanaka Y, Majid S, Nakagawa M, Igawa M, Dahiya R: Wnt antagonist family genes as biomarkers for diagnosis, staging, and prognosis of renal cell carcinoma using tumor and serum DNA. Clin Cancer Res 2006, 12:6989-6997.

46. Suzuki M, Shigematsu $H$, Nakajima $T$, Kubo R, Motohashi S, Sekine Y, Shibuya K, lizasa T, Hiroshima K, Nakatani Y, Gazdar AF, Fujisawa T: Synchronous alterations of Wnt and epidermal growth factor receptor signaling pathways through aberrant methylation and mutation in non small cell lung cancer. Clin Cancer Res 2007, 13:6087-6092. 